\title{
BMJ
}

\section{Folic acid supplements and risk of facial clefts: national population based case-control study}

\author{
Allen J Wilcox, senior investigator, ${ }^{1}$ Rolv Terje Lie, professor, ${ }^{2}$ Kari Solvoll, retired, ${ }^{3}$ Jack Taylor, senior \\ investigator, ${ }^{1}$ D Robert McConnaughey, senior programmer, ${ }^{4}$ Frank Åbyholm, professor, ${ }^{5}$ Hallvard \\ Vindenes, consultant plastic surgeon, ${ }^{6}$ Stein Emil Vollset, professor, ${ }^{2}$ Christian A Drevon, professor ${ }^{3}$
}

${ }^{1}$ Epidemiology Branch, National Institute of Environmental Health Sciences/NIH, Durham, NC 27709. USA

${ }^{2}$ Department of Public Health and Primary Health Care, Section for Epidemiology and Medical Statistics, University of Bergen, Norway

${ }^{3}$ Department of Nutrition, Institute of Basic Medical Sciences, Faculty of Medicine, University of Oslo, Oslo, Norway

${ }^{4}$ WESTAT, Durham, NC

${ }^{5}$ Department of Plastic Surgery, Rikshospitalet, Oslo

${ }^{6}$ Department of Plastic Surgery, Haukeland University Hospital,

Bergen

Correspondence to:

AJ Wilcox

wilcox@niehs.nih.gov

doi: 10.1136/bmj.39079.618287.0B

\section{ABSTRACT}

Objective To explore the role of folic acid supplements, dietary folates, and multivitamins in the prevention of facial clefts.

Design National population based case-control study. Setting Infants born 1996-2001 in Norway.

Participants 377 infants with cleft lip with or without cleft palate; 196 infants with cleft palate alone; 763 controls. Main outcome measures Association of facial clefts with maternal intake of folic acid supplements, multivitamins, and folates in diet.

Results Folic acid supplementation during early pregnancy ( $\geq 400 \mu \mathrm{g} /$ day) was associated with a reduced risk of isolated cleft lip with or without cleft palate after adjustment for multivitamins, smoking, and other potential confounding factors (adjusted odds ratio 0.61, $95 \%$ confidence interval 0.39 to 0.96 ). Independent of supplements, diets rich in fruits, vegetables, and other high folate containing foods reduced the risk somewhat (adjusted odds ratio $0.75,0.50$ to 1.11). The lowest risk of cleft lip was among women with folate rich diets who also took folic acid supplements and multivitamins ( 0.36 , 0.17 to 0.77 ). Folic acid provided no protection against cleft palate alone (1.07, 0.56 to 2.03).

Conclusions Folic acid supplements during early pregnancy seem to reduce the risk of isolated cleft lip (with or without cleft palate) by about a third. Other vitamins and dietary factors may provide additional benefit.

\section{INTRODUCTION}

The discovery that folic acid in early pregnancy reduces the risk of neural tube defects is one of the important public health advances of recent years. ${ }^{1}$ Even before folic acid deficiency had been linked to neural tube defects, it was known to produce facial clefts in rodents. ${ }^{2}$ However, studies of an association with facial clefts in humans have provided inconsistent results, ${ }^{3-8}$ and the question remains unresolved. ${ }^{9}$

This question is especially relevant in countries where fortification of foods with folic acid has not been allowed. One of these is Norway, which has one of the highest rates of facial clefts in Europe. ${ }^{10}$ We assessed possible effects of folic acid on facial clefts in Norway through a population based case-control study.

\section{METHODS}

Study design

Infants born in Norway with orofacial clefts are treated at government expense in one of two surgical centres (Oslo and Bergen). We contacted the families of all newborn infants born from 1996 to 2001 who had been referred for surgical treatment of a cleft (either cleft lip with or without cleft palate or cleft palate only). During the same years, we randomly selected an average of four per thousand live births (identified through the medical birth registry of Norway) as controls. These babies served as controls for both case groups, with a case:control ratio of about 1:2 for cleft lip with or without cleft palate, and 1:4 for cleft palate only. Mothers and fathers provided informed consent.

\section{Data collection}

Mothers completed two mailed questionnaires. The main questionnaire collected data on demographic characteristics; reproductive history; and smoking, alcohol, drugs, and other exposures during early pregnancy. The median time from the baby's delivery to completion of the main questionnaire was 14 weeks for cases and 15 weeks for controls (interquartile range 13-17 weeks).

After returning the main questionnaire, mothers were sent a second questionnaire on nutrition. This quantitative food frequency questionnaire was developed for the Norwegian diet and has been assessed for accuracy, validity, and reliability among diverse groups of Norwegian adults. ${ }^{11-13}$ We adapted this questionnaire slightly for women of reproductive age and asked women to recall their diet during the first three months of pregnancy. The main questionnaire and the nutritional questionnaire are available online (dir. niehs.nih.gov/direb/studies/ncl/question.htm).

We used three sources to identify non-cleft birth defects among cases: the medical birth registry (based on delivery records and hospital records during the first week of life), medical records at the hospital doing the corrective surgery, and the mothers' questionnaire. For the analysis of "isolated clefts," we excluded cases with a non-cleft birth defect ascertained from any of these sources. 


\section{Intake of folic acid supplements}

For each of the six months preceding pregnancy and each of the first three months of pregnancy, mothers were asked whether they took folic acid supplements and, if so, the specific product name. We contacted women who reported taking folic acid and asked them to send an empty pill bottle or label to the study office, so that staff could confirm the contents and dosage.

To be consistent with previous clefts studies ${ }^{78}$ we defined a three month exposure window for folate intake comprising the month before the last menstrual period and the first two months of pregnancy. (Facial structures that form the embryonic lip fuse during the fifth and sixth weeks of life, about eight weeks after the last menstrual period, whereas the palatal shelves fuse during weeks seven to $10 .{ }^{14}$ ) We counted women as exposed if they took folic acid for at least one month during this window; $81 \%$ of exposed women took folic acid for at least two of the three months.

Women who reported using folic acid supplements were asked in which specific months they took them and how often they took them. Among women who reported taking folic acid, we were able to confirm intake for $99 \%$ by using the product name or pill bottle label.

Specific dose was unavailable for 19\% of women taking folic acid. We imputed missing doses as follows. Before 1999, folic acid supplements of $400 \mu \mathrm{g}$ were unavailable in Norway except by prescription. Norway changed this policy in $1998,{ }^{15}$ and $400 \mu \mathrm{g}$ preparations became available over the counter. This change was reflected in our data: most women taking folic acid before 1999 were taking less than $400 \mu \mathrm{g}$, while $85 \%$ of women taking folic acid after 1998 took $400 \mu \mathrm{g}$ or more. Accordingly, when dose was missing, we imputed $100 \mu \mathrm{g}$ up to 1998 and $400 \mu \mathrm{g}$ thereafter.

Women were asked similar questions about multivitamins; we again collected brand names, empty bottles, and labels for documentation. Fifty six per cent of multivitamins contained folic acid. Among those with known dose of folic acid, 70\% provided $100 \mu \mathrm{g}$ or less (median $100 \mu \mathrm{g}$ ). For women who took multivitamins containing folic acid at an unknown dose, we imputed $100 \mu \mathrm{g}$.

We estimated each woman's total folic acid intake from folic acid supplements and multivitamins based on the folic acid dosage (known or imputed) and the frequency of intake. The standard recommendation in Norway (as elsewhere) is $400 \mu \mathrm{g}$ folic acid a day in the periconceptional period. ${ }^{15}$ Fifty five per cent of women who took folic acid supplements got an average of 400$500 \mu \mathrm{g}$ folic acid a day; only $12 \%$ got higher doses. Accordingly, we categorised perinatal folic acid intake into three groups: none, less than the current recommended daily dose (1-399 $\mu \mathrm{g})$, and the recommended daily dose $(\geq 400 \mu \mathrm{g})$. For dichotomous analyses, we assessed folic acid as $<400 \mu \mathrm{g}$ or $\geq 400 \mu \mathrm{g}$ a day, consistent with previous studies. ${ }^{37}$

\section{Intake of dietary folates}

We estimated dietary folate intake by applying official Norwegian food composition tables to mothers' responses on the food frequency questionnaire, with adjustments for the usual methods of food preparation. We categorised dietary folate a priori into quarters on the basis of the folate distribution among controls.

\section{RESULTS}

\section{Participants}

Among the nearly 300000 women who delivered in Norway during the time of our study (1996-2001), 676 mothers had a baby with an orofacial cleft referred for corrective surgery. We excluded 24 mothers who did not speak Norwegian or whose baby died after birth, leaving 652 eligible case mothers. Of these, $88 \%$ (573) agreed to participate (377 with cleft lip with or without cleft palate and 196 with cleft palate only). We randomly selected 1022 live births within six weeks of delivery to serve as controls. After we excluded 16 mothers who were not Norwegian speakers or whose baby died, 1006 control mothers were eligible, of whom $76 \%$ (763) agreed to participate.

More than 95\% of mothers were married or living as if married. Mean maternal age was 29 years, and about $40 \%$ of mothers delivered for the first time. Ten per cent of control mothers took $\geq 400 \mu \mathrm{g}$ folic acid supplements as well as multivitamins in early pregnancy, $9 \%$ took folic acid alone, and 26\% took multivitamins alone. Among the cases, $17 \%$ of babies with cleft lip with or without cleft palate also had some other birth defect, and $40 \%$ of those with cleft palate only had accompanying defects (table 1).

\section{Folic acid supplement}

Table 2 shows odds ratios for clefts with folic acid supplements. The crude odds ratio with folic acid of $\geq 400 \mu \mathrm{g} /$ day was 0.66 (95\% confidence interval 0.47 to 0.95 ) for cleft lip with or without cleft palate and 0.81 (0.53 to 1.26) for cleft palate only. Associations were present only among the cases with isolated clefts (that is, those with no other birth defects; data not shown). We therefore restricted subsequent analyses to the isolated clefts. Adjustment for potential confounding factors (diet and multivitamins, mother's education, mother's employment during early pregnancy, smoking, alcohol consumption, and year of baby's birth) slightly weakened the association between folic acid and cleft lip with or without cleft palate and removed the association entirely for cleft palate only. Lacking any evidence of an effect of folic acid on cleft palate only (odds ratio 1.07, 0.56 to 2.03 ), we focused the remainder of the analysis on cleft lip with or without cleft palate.

We explored additional adjustments for parity, age of mother and father, marital status, and measures of family income, all of which produced little or no change in estimates. Results were also unchanged after exclusion of women with imputed values for folic acid.

None of the analyses, either crude or adjusted, suggested any association of low dose folic acid $(<400 \mu \mathrm{g} /$ day) with clefting. In the dichotomous analysis of folic acid $(<400 \mu \mathrm{g} /$ day $v \geq 400 \mu \mathrm{g} /$ day $)$, the adjusted 
relative risk for isolated cleft lip with or without cleft palate was 0.61 (0.39 to 0.96$)$.

\section{Dietary folates}

The estimated median intake of dietary folates (adjusted for usual method of cooking) was 205 (interquartile range 160-260) $\mu \mathrm{g} /$ day. Dietary folate intake across quarters was moderately associated with the crude risk of cleft lip with or without cleft palate $(\mathrm{P}$ for trend $=0.03$ ) (table 3). The relative risk for women above the median compared with those below was 0.78 (0.61 to 1.01). Adjustment for covariates weakened this risk slightly $(0.80,0.60$ to 1.08$)$.

\section{Multivitamins}

Intake of multivitamins around conception showed a similarly modest association with reduced risk of cleft lip with or without cleft palate (crude odds ratio 0.77, 0.57 to 1.03). Adjustment for covariates (including folic acid) again produced minimal change $(0.75,0.50$ to 1.11$)$.

\section{Combining three sources of folic acid and vitamins}

The figure shows adjusted odds ratios for eight groups of mothers, categorised by whether the mothers were above or below the median for dietary folate, whether they were taking multivitamins around conception (yes or no), and whether they were taking $\geq 400 \mu \mathrm{g}$ folic acid around conception (yes or no). Women with lower measures in all three categories are the reference group. The groups at lowest risk were those who took $\geq 400 \mu \mathrm{g}$ of folic acid in combination with multivitamins or good diet. The estimated relative risk among women with all three $(\geq 400 \mu \mathrm{g}$ folic acid plus multivitamins and healthy diet) was 0.36 (0.17 to 0.77 ).

\section{DISCUSSION}

We found evidence that folic acid supplementation of $400 \mu \mathrm{g}$ or more a day reduces the risk of isolated cleft lip with or without cleft palate by a third, with no apparent effect on the risk of cleft palate alone. Separate findings for the two types of orofacial clefts are consistent with embryological and epidemiological data that show distinct causal mechanisms for these two types of defects. ${ }^{16}$ Multivitamins and a diet rich in vegetables and fruits may also be protective for cleft lip with or without cleft palate, although these effects (if real) are weaker. The fact that perinatal multivitamins and folic acid supplements were often taken separately in Norway allowed us to distinguish the association of cleft lip with or without cleft palate with folic acid from the weaker association with multivitamins alone - a distinction not possible in earlier studies.

\section{Strengths and weaknesses}

Study design-Cases were drawn from a large and well defined population, with virtually complete ascertainment, a high participation rate $(88 \%)$, and clinical confirmation of all defects. Although the participation rate was lower for controls $(76 \%)$, the controls had the advantage of being drawn randomly from the entire
Table 1 Demographic and other characteristics of mothers and children, cases and controls, Norway 1996-2001. Values are numbers (percentages)

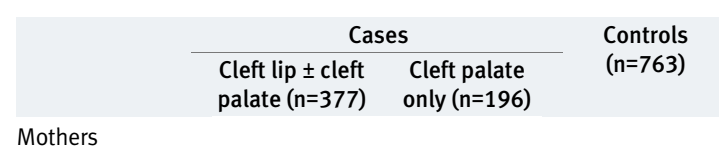

Mothers

Age (years):

\begin{tabular}{lccc}
\hline$<20$ & $8(2)$ & $6(3)$ & $12(1)$ \\
\hline $20-29$ & $199(53)$ & $105(54)$ & $408(54)$ \\
\hline $30-39$ & $165(44)$ & $81(41)$ & $328(43)$ \\
\hline$\geq 40$ & $5(1)$ & $4(2)$ & $15(2)$ \\
\hline $\begin{array}{l}\text { Education less } \\
\text { than high school }\end{array}$ & $70(19)$ & $23(12)$ & $87(11)$ \\
\hline Employment in & $297(79)$ & $158(81)$ & $646(85)$
\end{tabular}

early pregnancy

Folic acid supplement*:

\begin{tabular}{llll}
\hline None & $240(64)$ & $119(61)$ & $453(59)$ \\
\hline $1-399 \mu \mathrm{g}$ & $86(23)$ & $46(23)$ & $165(22)$ \\
\hline$\geq 400 \mu \mathrm{g}$ & $51(14)$ & $31(16)$ & $145(19)$
\end{tabular}

Dietary folate, $\mu \mathrm{g}$ (quarters)

\begin{tabular}{|c|c|c|c|}
\hline $0-171$ & $111(31)$ & $62(33)$ & $176(25)$ \\
\hline $172-214$ & $88(25)$ & $44(23)$ & $177(25)$ \\
\hline $215-264$ & $81(23)$ & 36 (19) & $177(25)$ \\
\hline$\geq 265$ & $74(21)$ & $46(25)$ & $174(25)$ \\
\hline Multivitamins* & $123(33)$ & $71(36)$ & $279(37)$ \\
\hline \multicolumn{4}{|c|}{ Cigarette smoking†: } \\
\hline No exposure & $152(40)$ & $92(47)$ & $414(54)$ \\
\hline Passive only & $58(15)$ & $32(16)$ & $106(14)$ \\
\hline Active, 1-5 & $93(25)$ & $36(18)$ & 142 (19) \\
\hline Active, 6-10 & $49(13)$ & $31(16)$ & $73(10)$ \\
\hline Active, $\geq 11$ & $25(7)$ & $5(3)$ & $28(4)$ \\
\hline \multicolumn{4}{|c|}{ Alcoholic beveragesł: } \\
\hline 0 & $230(61)$ & $120(61)$ & 527 (69) \\
\hline $1-3$ & 70 (19) & 37 (19) & $123(16)$ \\
\hline $4-6$ & $26(7)$ & $17(9)$ & $40(5)$ \\
\hline$\geq 7$ & $45(12)$ & $22(11)$ & $68(9)$ \\
\hline Missing & $6(2)$ & 0 & $5(1)$ \\
\hline \multicolumn{4}{|l|}{ Infants } \\
\hline $\begin{array}{l}\text { Other birth } \\
\text { defects }\end{array}$ & $63(17)$ & $78(40)$ & $38(5)$ \\
\hline
\end{tabular}

population of births. Our study was designed to test the folate hypothesis. Women were contacted as soon as possible after delivery to reduce the recall interval. We cannot reconstruct the mothers' complete exposure history retrospectively, but the collection of brands, bottles, and labels allowed us to correct some errors in self report.

Data quality-Folic acid is a synthetic folate dispensed in well calibrated doses. Although error in measurement inevitably occurs (for example, owing to missing data or errors in reported frequency of intake), folic acid is estimated more reliably than dietary folates. Nutritional assessment is notoriously inexact. In addition, our measure of dietary folate (based on recalled intake of fruit and vegetables) probably 
captures many aspects of good nutrition, and the observed association with dietary folate could reflect the effects of other vitamins in addition to folates.

Bias-As in all case-control studies, recall bias is a concern. We sent the main questionnaire to women around three months after delivery, much earlier than in many previous studies. Concerns about recall bias were further reduced by the specificity of the findings. In our data, the association with folic acid was strong for cleft lip with or without cleft palate but absent for cleft palate only. This is consistent with previous positive studies, which have found associations more often with cleft lip with or without cleft palate than with cleft palate only. ${ }^{367}$ Also, recall bias would presumably operate among all women who took folic acid, not only those who took the higher doses. The fact that folic acid less than $400 \mu \mathrm{g}$ a day showed no association with clefts suggests a lack of recall bias.

Confounding-Confounding is a general threat to observational studies, particularly when the response rate is higher among cases than among controls. Differential participation by social class or other confounding characteristics could contribute to the observed associations. However, adjustments for social factors, alcohol, smoking, and other potential confounding variables had little impact on the estimates. This weak evidence for confounding in the analysis reduces the likelihood

Table 2 | Crude and adjusted odds ratios ( $95 \%$ confidence intervals) for cleft lip with and without cleft palate and cleft palate only, for three categories of folic acid supplementation

\begin{tabular}{|c|c|c|c|c|}
\hline \multirow{2}{*}{$\begin{array}{l}\text { Folic acid } \\
\text { supplement } \\
(\mu \mathrm{g} / \text { day) }\end{array}$} & \multirow[t]{2}{*}{ All cases: crude risk } & \multicolumn{3}{|c|}{ Isolated clefts } \\
\hline & & Crude risk & $\begin{array}{l}\text { Crude risk (restricted to } \\
\text { subset with complete data) }\end{array}$ & Adjusted risk* \\
\hline \multicolumn{5}{|c|}{ Cleft lip with or without cleft palate } \\
\hline & $(n=377)$ & $(n=314)$ & $(n=287)$ & $(n=287)$ \\
\hline 0 & 1.0 & 1.0 & 1.0 & 1.0 \\
\hline $1-399$ & $0.98(0.73$ to 1.33$)$ & 0.97 (0.70 to 1.35$)$ & 0.97 (0.69 to 1.36$)$ & $1.17(0.75$ to 1.84$)$ \\
\hline$\geq 400$ & $0.66(0.47$ to 0.95$)$ & $0.58(0.39$ to 0.86$)$ & 0.57 (0.38 to 0.85$)$ & $0.65(0.40$ to 1.05$)$ \\
\hline \multicolumn{5}{|c|}{ Cleft palate only } \\
\hline & $(n=196)$ & $(n=118)$ & $(n=114)$ & $(n=114)$ \\
\hline 0 & 1.0 & 1.0 & 1.0 & 1.0 \\
\hline $1-399$ & $1.06(0.72$ to 1.56$)$ & $1.02(0.63$ to 1.66$)$ & 1.09 (.067 to 1.79$)$ & $0.98(0.51$ to 1.90$)$ \\
\hline$\geq 400$ & $0.81(0.53$ to 1.26$)$ & $0.90(0.54$ to 1.52$)$ & $0.92(0.55$ to 1.57$)$ & 1.07 (0.56 to 2.03$)$ \\
\hline
\end{tabular}

Table 3 |Crude and adjusted odds ratios ( $95 \%$ confidence intervals) for isolated cleft lip with or without cleft palate associated with dietary folate

\begin{tabular}{|c|c|c|c|}
\hline \multirow[t]{2}{*}{$\begin{array}{l}\text { Dietary folate } \\
\text { (quarters) }\end{array}$} & \multirow[t]{2}{*}{ All (354 cases; 704 controls): crude risk } & \multicolumn{2}{|c|}{$\begin{array}{l}\text { Subset with complete data (287 cases; } 664 \\
\text { controls) }\end{array}$} \\
\hline & & Crude risk & Adjusted risk $\dagger$ \\
\hline Q1 & 1.0 & 1.0 & 1.0 \\
\hline Q2 & $0.86(0.59$ to 1.26$)$ & $0.86(0.59$ to 1.26$)$ & $0.97(0.65$ to 1.46$)$ \\
\hline Q3 & $0.71(0.49$ to 1.05$)$ & $0.70(0.47$ to 1.03$)$ & $0.75(0.49$ to 1.14$)$ \\
\hline Q4 & $0.75(0.51$ to 1.11$)$ & 0.74 (0.50 to 1.09$)$ & $0.80(0.52$ to 1.24$)$ \\
\hline P for trend & 0.03 & 0.07 & 0.21 \\
\hline
\end{tabular}

of residual confounding by these or other closely related factors. We cannot rule out the presence of unmeasured confounders, although such confounders would have to be strongly related to cleft lip with or without cleft palate in order to produce the observed results.

\section{Comparisons with previous human studies}

Previous evidence from epidemiological studies of folic acid and clefts has been mixed.$^{3-7}$ Some ambiguity in previous studies may reflect the relatively weaker association of folic acid with clefts compared with neural tube defects. Furthermore, most of the earlier clefts studies were not specifically designed to test the folic acid hypothesis, few were able to distinguish intake of folic acid from intake of multivitamins, and none sought documentation of reported intake. Recently, van Rooij and colleagues reported a protective effect on isolated cleft lip with or without cleft palate with folic acid supplement alone, ${ }^{7}$ although this study was limited by a small sample and a haphazard set of controls. The plausibility of a specific role for folic acid in preventing cleft lip is further supported (albeit indirectly) by a study of pregnant women taking drugs that can act as folic acid antagonists. ${ }^{17}$ An increased risk of facial clefts was reported among the prenatally exposed infants. No previous studies have collected information on daily folic acid intake less than $400 \mu \mathrm{g}$, and so we are unable to compare our finding of an apparent threshold effect with other studies.

\section{Contribution of other vitamins}

The finding that the relatively low levels of dietary folates (which are less bioavailable than folic acid) seemed to be weakly protective against cleft lip with

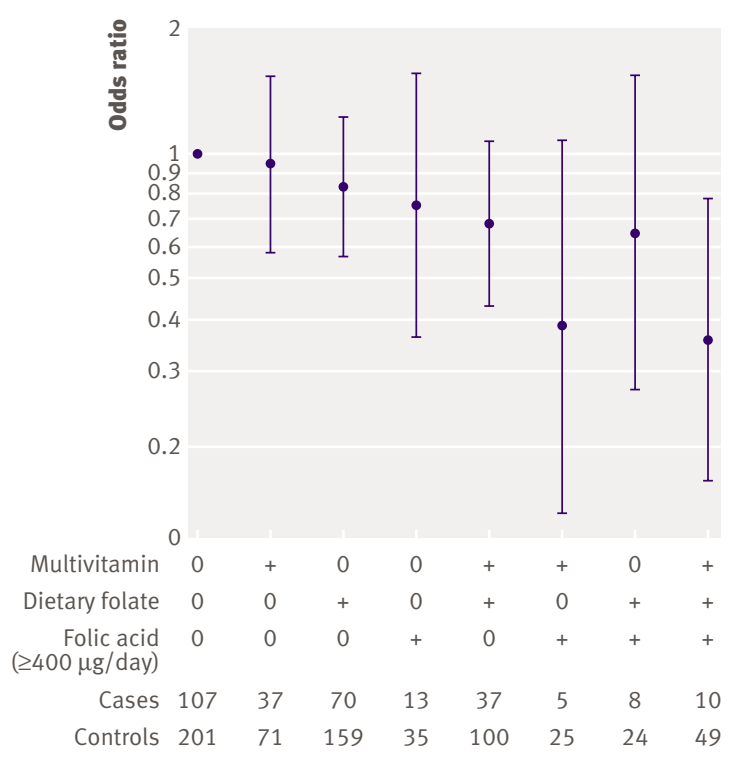

Odds ratios for cleft lip with or without cleft palate in women divided into eight categories according to their intake of folic acid ( $\geq 400 \mu \mathrm{g}$ folic acid $v$ all others), dietary folate (above or below the median), and multivitamins (yes or no). Numbers of women in each category are shown beneath the figure 


\section{WHAT IS ALREADY KNOWN ON THIS TOPIC}

Folic acid supplementation in the periconceptional period reduces the risk of neural tube defects

Benefits from folates in the prevention of other birth defects have not been established

\section{WHAT THIS STUDY ADDS}

The risk of cleft lip with or without cleft palate seems to be substantially reduced by folic acid supplements during the month before pregnancy and the first two months of pregnancy

Similar benefits are not apparent for cleft palate

\section{Conclusion}

Intake of $400 \mu \mathrm{g}$ a day or more of folic acid in the periconceptional period seems to reduce the risk of isolated cleft lip with or without cleft palate in Norway by about a third. This apparent effect of folic acid is relevant to ongoing discussions about food fortification. If folic acid is able to prevent a major birth defect in addition to neural tube defects, this benefit should be included among the risks and benefits of fortifying foods with folic acid, a matter of ongoing controversy in many countries. ${ }^{23}$

We are indebted to the dedicated staff who did the fieldwork for this study (Maria Acuero, Nina Hovland, Aase Gunn Mjaatvedt, Gunnar mlid, and Lil Stallone). We thank Donna Baird, Olga Basso, Freya Kamel, Matthew Longnecker, Ron Munger, Ruby Nguyen, Dale Sandler, Min Shi, and Clarice Weinberg for useful criticisms of earlier drafts of this paper.

Contributors: All authors made substantial contributions to the intellectual content of the manuscript and all have approved the final version. AJW originated the study, designed the field work, analysed the data, contributed critical insights in interpretation of data, and had primary responsibility for writing the paper. RTL originated the study, designed and supervised the field work, helped in analysis of data, and contributed critical insights in interpretation of data. KS contributed to the design of the field study, supervised the scanning and interpretation of the food frequency questionnaire, and participated in the interpretation of data. JT contributed substantially to the design of the field study. DRMcC made substantial contributions to the cleaning of the data, did the programming for data analysis, and contributed critical insights in interpretation. F contributed to the design of the field study, provided clinical access to cases, and contributed critical insights in interpretation of data. HV contributed to the design of the field study, provided clinical access to cases, and contributed critical insights in interpretation of data. SEV contributed to the design of the field study and participated in the interpretation of data. CAD contributed to the design of the field study, designed the food frequency questionnaire, and participated in the interpretation of data. AJW is the guarantor.

Funding: Intramural Research Program of the NIH, National Institute of Environmental Health Sciences (NIEHS), the Johan Throne Holst Foundation for Nutrition Research, and the Thematic Area of Perinatal Nutrition at the Medical Faculty of University of Oslo, Norway.

Competing interests: None declared.

Ethical approval: Norwegian Data Inspectorate and Regional Medical Ethics Committee of Western Norway.

1 Botto LD, Moore CA, Khoury MJ, Erickson JD. Medical progress: neural tube defects. N Engl J Med 1999;341:1509-19.

2 Munger RG. Maternal nutrition and oral clefts. In: Wyszynski DF, ed. Cleft lip and palate: from origin to treatment. Oxford: Oxford University Press, 2002:170-92.

3 Shaw GM, Lammer EJ, Wasserman CR, O'Malley CD, Tolarova MM. Risks of orofacial clefts in children born to women using multivitamins containing folic acid periconceptionally. Lancet 1995;346:393-6.

4 Hayes C, Werler MM, Willett WC, Mitchell AA. Case-control study of periconceptional folic acid supplementation and oral clefts. Am J Epidemiol 1996;143:1229-34.

5 Werler MM, Hayes C, Louik C, Shapiro S, Mitchell AA. Multivitamin supplementation and risk of birth defects. Am J Epidemiol 1999;150:675-82.

6 Itikala PR, Watkinds ML, Mulinare J, Moore CA, Liu Y. Maternal multivitamin use and orofacial clefts. Teratology 2001;63:79-86.

7 Van Rooij IA, Ocke MC, Straatman H, Zielhuis GA, Merkus HM, Steegers-Theunissen RP. Periconceptional folate intake by supplement and food reduces the risk of nonsyndromic cleft lip with or without cleft palate. Prev Med 2004;39:689-94.

8 Shaw GM, Carmichael SL, Laurent C, Rasmussen SA. Maternal nutrient intakes and risks of human orofacial clefts. Epidemiol 2006;17:285-91.

9 Bailey LB, Berry RJ. Folic acid supplementation and the occurrence of congenital heart defects, orofacial clefts, multiple births, and miscarriage. Am J Clin Nutr 2005;81(suppl):1213-7S.

10 Mossey PA, Little J. Epidemiology of oral clefts: an international perspective. In: Wyszynski DF, ed. Cleft lip and palate: from origin to treatment. Oxford: Oxford University Press, 2002:170-92. population level changes in rare diseases may contribute to this inconclusive evidence. 
11 Nes M, Andersen LF, Solvoll K, Sandstad B, Hustvedt BE, Løvø A, et al. Accuracy of a quantitative food frequency questionnaire applied in elderly Norwegian women. Eur J Clin Nutr 1992;46:809-21.

12 Solvoll K, Lund-Larsen K, Søyland E, Sandstad B, Drevon CA. A quantitative food frequency questionnaire evaluated in a group of dermatologic outpatients. Scand J Nutr 1993;37:150-5.

13 Andersen LF, Tomten H, Haggarty P, Løvø A, Hustvedt B-E. Validation of energy intake estimated from a food frequency questionnaire: a doubly labelled water study. Eur J Clin Nutr 2003;57:279-84.

14 Diewert VM. Development of human craniofacial morphology during the late embryonic and early fetal periods. Am J Orthod 1985;88:64-76.

15 Daltveit AK, Vollset SE, Lande B, Øien H. Changes in knowledge and attitudes of folate, and use of dietary supplements among women of reproductive age in Norway 1998-2000. Scand J Public Health 2004;32:264-71.

16 Christensen K. Methodological issues in epidemiological studies of oral clefts. In: Wyszynski DF, ed. Cleft lip and palate: from origin to treatment. Oxford: Oxford University Press, 2002:101-7.
17 Hernandez-Diaz S, Werler MM, Walker AM, Mitchell AA. Folic acid antagonists during pregnancy and the risk of birth defects. N Engl Med 2000;343:1608-14.

18 Khoury MJ, Flanders WD, James LM, Erickson JD. Human teratogens, prenatal mortality, and selection bias. Am J Epidemiol 1989;130:361-70.

19 Ray JG, Meier C, Vermeulen MJ, Wyatt PR, Cole DE. Association between folic acid food fortification and congenital orofacial clefts. Pediatr 2003;143:805-7.

20 Bille C, Knudsen LB, Christensen K. Changing lifestyles and oral clefts occurrence in Denmark. Cleft Palate Craniofac J 2005;42:255-9.

21 Yadzy MM, Honein MA, Xing J. Impact of folic acid supplementation on orofacial clefts [abstract]. Am J Epidemiol 2006;163(suppl):S52.

22 Busby A, Armstrong B, Dolk H, Armstrong N, Haeusler M, Berghold A, et al. Preventing neural tube defects in Europe: a missed opportunity. Reprod Toxicol 2005;20:393-402.

23 Rosenberg $\mathrm{IH}$. Science-based micronutrient fortification: which nutrients, how much, and how to know? Am J Clin Nutr 2005;82:279-80.

Accepted: 18 December 2006 